\title{
Salvia miltiorrhiza Inhibit Vascular Smooth Muscle Cells Proliferation with Antioxidative Effect
}

\author{
Yu-chiang Hung* \\ Department of Chinese Medicine, Kaohsiung Chang Gung Memorial Hospital and Chang Gung University, Taiwan
}

Submission: June 9, 2017; Published: August 16,2017

*Corresponding author: Yu-chiang Hung, Department of Chinese Medicine, Kaohsiung Chang Gung Memorial Hospital and Chang Gung University, Taiwan, Tel: +886-731-7123; Fax: +886-731-7123; Email: d.fathallah@agu.edu.bh

\begin{abstract}
Vascular smooth muscle cells (VSMCs) proliferation plays a key role in the pathogenesis of atherosclerosis which is the main cause of cardiovascular or cerebrovascular deaths worldwide. This study aims to explore whether SM has antioxidant effects to inhibit VSMCs proliferation on the cultured rat aortic smooth muscle A10 cells. Cell viability assay, intracellular reactive oxygen species (ROS) measurement and thiobarbituric acid-reactive substance assay were applied. One way analysis of variance and Scheffe test were used for the statistical analysis. The results demonstrated that homocysteine could induce more cell viability, intracellular ROS and lipid peroxidation of VSMCs, but reduced by Salvia miltiorrhiza (SM) or N-acetyl cysteine (NAC) treatment. Both SM and NAC can significantly decrease cell viability, intracellular ROS and lipid peroxidation on the rest or homocysteine- induced VSMCs. SM can inhibit VSMCs proliferation with suppressing intracellular ROS and lipid peroxidation.
\end{abstract}

\section{Introduction}

Atherosclerosis is the global burden [1,2] and the leading causes of morbidity and mortality of ischemic heart disease, stroke, and peripheral vascular diseases all over the world $[3,4]$. They resulted in 247.9 deaths per 100,000 persons, accounting for $84.5 \%$ of cardiovascular or cerebrovascular deaths and $28.2 \%$ of all-cause mortality in 2013 [5]. VSMCs proliferation would play a key role in the pathogenesis of atherosclerosis $[6,7]$. Their phenotype would change from a contractile phenotype in quiescent state to a active synthetic phenotype in the pathologic process of atherosclerosis [8]. They would change from oval to spindle shape then.

Salvia mltiorrhiza (SM) known as "Danshen" in traditional Chinese medicine was commonly used to treat the blood stasis syndrome [9,10] cancers [11,12] and atherosclerosis related vascular diseases [13,14] for thousands of years in Asia. Previous population- based studies also found that SM was the most common Chinese herb used to treat heart disease $[15,16]$ and stroke $[17,18]$.

The purpose of this study is to find out whether SM has antioxidant effects to inhibit VSMCs proliferation on the cultured rat aortic smooth muscle A10 cells .In addition to the general control group, both negative control with homocysteine $[19,20]$ and positive control with antioxidant NAC [21,22] were used for SM research on the cultured A10 cells.

\section{Materials and Methods}

\section{Preparation of herbal extract Salvia mltiorrhiza}

The roots of cultivated Salvia miltiorrhiza Bunge were purchased from a Traditional Chinese Medicine dispensary in Taiwan. The $400 \mathrm{~g}$ of this Salvia miltiorrhiza root was cut into $0.5 \mathrm{~cm}$ long pieces and boiled in $500 \mathrm{~mL}$ of freshly double distilled and deionized water under reflux condition through $1 \mathrm{~h}$. After that, the mixture was filtered through a Type JH membrane filter $(0.45 \mathrm{~m}, 47 \mathrm{~mm}$ Id, Millipore, Bedford, MA, USA $)$ and the filtrate was carefully collected. Next, further $500 \mathrm{~mL}$ water was added to the residue and boiled for $1 \mathrm{~h}$. The filtrate was collected again and combined with the previous filtrate sample and cooled to ambient temperature. Final powdered form of the aqueous extract of Salvia miltiorrhiza root was obtained by freeze-drying at $-40{ }^{\circ} \mathrm{C}$ to a light brownish residue with an approximate yield of $76 \mathrm{~g}$ (ca. 19.0\%) using Alpha 2-4LSC apparatus (Martin Christ, Osterode, Germany). The crude sterile SM extract was stored at $-20{ }^{\circ} \mathrm{C}$ until further use in all subsequent experiments. The concentration used in each experiment was calculated upon the dry weight of the Salvia miltiorrhiza extract $(\mathrm{mg} / \mathrm{mL})$ which was resuspended in freshly prepared double distilled and deionized water as purified by Milli-Q filtration system (Millipore). SM $0.015 \mathrm{mg} / \mathrm{ml}$ would be used in this study. 


\section{Rat aortic smooth muscle cells culture}

The rat A10 cells line, a vascular smooth muscle cells (VSMCs) line isolated from rat thoracic embryonic aorta [23], was purchased from the Food Industry Research and Development Institute in Taiwan. Cells were routinely cultured in Dulbecco's modified Eagle medium (DMEM, Gibco Life Technologies, Sao Paulo, Brazil) containing $10.0 \%$ fetal bovine serum, penicillin (100units/mL), streptomycin $(100 \mathrm{~g} / \mathrm{mL})$ and $\mathrm{NaHCO} 3(3.7 \mathrm{~g} / \mathrm{L})$ and grown in humidified atmosphere of $5.0 \% \mathrm{CO} 2$ in air at 37 ${ }^{\circ} \mathrm{C}$. Cells were characterized as being vascular smooth muscle cells by immunofluorescence detection of alpha-smooth muscle actin (Sigma). Cells between passages 7 and 15 were used for experiments.

\section{MTT cell viability assay}

This assay is based on the capacity of mitochondrial enzymes (succinate dehydrogenase) in the cell to reduce thiazolyl blue tetrazolium bromide (MTT) to form insoluble product formazan [24]. The amount of $1.0 \times 10^{5}$ cells were seeded in 24 well tissue culture plates and replaced with or without $100 \mathrm{M}$ of homocysteine. Different groups including control, Salvia miltiorrhiza and antioxidant n-acetyl cysteine (NAC) were compared. For the growth-rate determination, after 3 days of culture, the isopropanol solution mixed with freshlymade MTT salt was added to wells in triplicate. Next, the optical density of dissolved material was measured spectrophotometrically at $560 \mathrm{~nm}$ with subtract background at $670 \mathrm{nmusing}$ a 96-well plate reader (Elx 800, Bio-Tek Instrument, Winooski, VT, USA).

\section{Measurement of reactive oxygen species(ROS)}

To assess the effect of SM on the cellular redox status, the intracellular ROS was measured by the fluorimetric assay with 2, 7 - dichlorofluorescin (DCFH) as described by Wang and
Joseph [25]. Briefly, 5M of the ROS prober dye in the form of 2, 7 -dichlorofluorescin diacetate (DCFH-DA) was added and incubated for $1 \mathrm{~h}$ at $37{ }^{\circ} \mathrm{C}$. Next, the rat A10 cells were washed with PBS, and fluorescence of DCFH was monitored in the PerkinElmer LS 5B fluorometer (Perkin-Elmer, Norwalk, CT, USA) with excitation at $485 \mathrm{~nm}$ and emission at $530 \mathrm{~nm}$, respectively.

\section{Thiobarbituric acid-reactive substance assay}

Thiobarbituric acid-reactive substances (TBARS) were determined according to the assay described by Janero [26] The antioxidant effect on lipid peroxidation was evaluated by determining malondialdehyde (MDA) level in the cultured VSMC medium via the thiobarbituric acid reacting substances method (Sigma). The cultured VSMC medium mixed with trichloracetic acid and thiobarbituric acid was boiled. $2 \mathrm{ml}$ butanol was then added to the each tube and results were obtained at $535 \mathrm{~nm}$ after centrifugation at $2500 \mathrm{rpm}$ for $10 \mathrm{~min}$.

\section{Statistical analysis}

All experiments were repeated 5 times and the results were expressed as means \pm standard error mean. One way analysis of variance and Scheffe test using SPSS software (SPSS Inc, Chicago, IL, USA) were applied for the statistical analysis. A value of $\mathrm{p}<0.05$ was considered to be statistically significant

\section{Results}

\section{Morphology change of A10 cells with Salvia miltiorrhiza}

A10 cells were authenticated as being VSMCs by immunofluorescence detection initially. After 3 days of A10 cells cultured, morphology of spindle synthetic phenotype of VSMCs without Salvia miltiorrhiza treatment were changed to irregular shape with Salvia miltiorrhiza treatment (Figure 1).
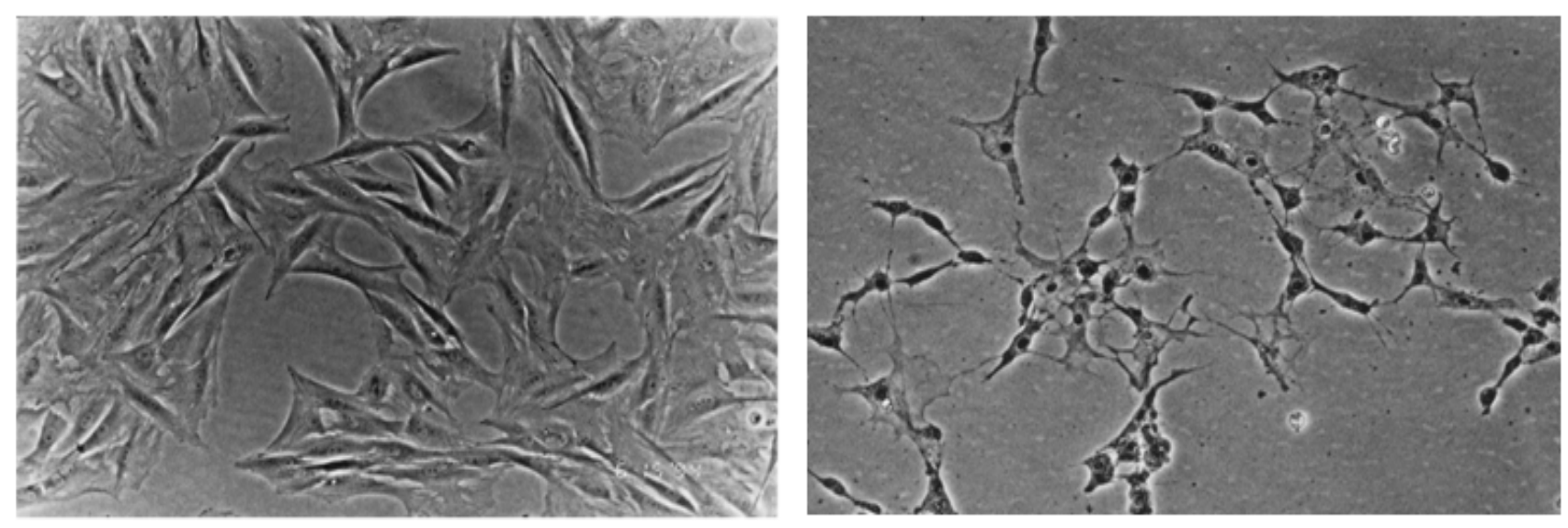

Figure 1: Morpholgy differences between rest cells and SM induced A10 cells. It shows spindle shape on the rest cells and irregular shape on the SM induced VSMCs.

\section{Inhibitory A10 cells viability with Salvia miltiorrhiza}

MTT results (Figure 2) showed the mean cell viability of control group was $47.45 \pm 1.49 \%$ on the rest cultured VSMC , but significantly decreased to $34.91 \pm 1.26 \%$ in the SM group or
$33.62 \pm 1.28 \%$ in the NAC group $(\mathrm{P}<0.001)$. Scheffe test (Table 1) revealed that the mean of difference $12.54 \pm 0.85 \%$ between control group and SM group was statistically significant (95\% CI: $10.167 \sim 14.910 \%$ ). The other mean of difference $13.83 \pm 0.85 \%$ 
between control group and NAC group was also statistically significant (95\% CI: 11.459 16.202\%). However, there was no significant difference $1.29 \pm 0.85 \%$ (95\% CI: $1.080 \sim 3.664 \%)$ between SM and NAC group. Homocysteine $(100 \mu \mathrm{M})$ can significantly stimulate A10 cells growth $(\mathrm{P}<0.001)$, but would be inhibited by SM or NAC treatment. The mean cell viability of control group was $100 \pm 0.00 \%$ on the homocysteine induced VSMC culture, but significantly decreased to $48.17 \pm 1.21 \%$ in the SM group or $48.01 \pm 0.80 \%$ in the NAC group $(\mathrm{P}<0.001)$. Scheffe test (Table 2) revealed that the mean of difference $51.83 \pm 0.53 \%$ between control group and SM group was statistically significant (95\% CI: 50.356 53.304\%). The other mean of difference $51.99 \pm 0.53 \%$ between control group and NAC group was also statistically significant (95\% CI: 50.518 53.466\%). However, there was no significant difference $0.16 \pm 0.53 \% \quad(95 \% \mathrm{CI}$ : $1.080 \sim 3.664 \%$ ) between SM and NAC group. The results demonstrated that SM $0.015 \mathrm{mg} / \mathrm{ml}$ and $\mathrm{NAC} 16 \mathrm{ng} / \mathrm{ml} \mathrm{did}$ inhibit the proliferation of A10 cells (Table 3). The inhibition phenomenon was more pronounced in the homocysteine induced VSMC growth.

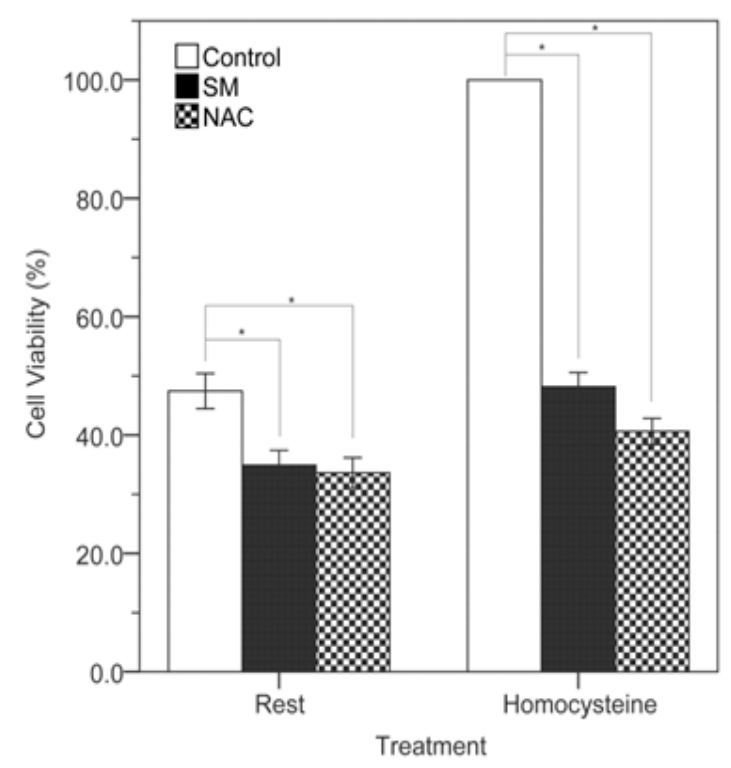

Figure 2: Effect of SM upon the A10 cells viability as measured by the MTT assay.

Table 1: Cell viability, ROS and lipid peroxidation differences compared with Scheffe method on Rest A10 cells.

\begin{tabular}{|c|c|c|c|c|}
\hline Homocysteine A10 & Group comparison & Mean $_{\text {diff }} \mathbf{\text { SD }}$ & P value & $\mathbf{9 5 \%}$ CI \\
\hline \multirow{3}{*}{ Cell Viability (\%) } & Control-SM & $51.83 \pm 0.53$ & 0.000 & $(50.356,53.304)$ \\
\cline { 2 - 5 } & Control-NAC & $51.99 \pm 0.53$ & 0.000 & $(50.518,53.466)$ \\
\cline { 2 - 5 } & SM-NAC & $0.16 \pm 0.53$ & 0.954 & $(-1.312,1.636)$ \\
\hline \multirow{3}{*}{ ROS (\%) } & Control-SM & $23.71 \pm 0.60$ & 0.000 & $(23.031,25.389)$ \\
\cline { 2 - 5 } & Control-NAC & $25.14 \pm 0.60$ & 0.000 & $(-0.247,3.111)$ \\
\cline { 2 - 5 } & SM-NAC & $1.43 \pm 0.60$ & 0.099 & $(0.174,0.213)$ \\
\cline { 2 - 5 } & Control-SM & $0.19 \pm 0.01$ & 0.000 & $(0.191,0.230)$ \\
\cline { 2 - 5 } & Control-NAC & $0.21 \pm 0.01$ & 0.000 & $(-0.003,0.036)$ \\
\hline
\end{tabular}

Table 2: Cell viability, ROS and lipid peroxidation differences compared with Scheffe method on homocysteine induced A10 cells.

\begin{tabular}{|c|c|c|c|c|}
\hline Rest A10 & Group comparison & Mean $_{\text {diff }} \mathbf{S D}$ & P value & $\mathbf{9 5 \%}$ CI \\
\hline \multirow{3}{*}{ Cell Viability (\%) } & Control-SM & $12.54 \pm 0.85$ & 0.000 & $(10.167,14.910)$ \\
\cline { 2 - 5 } & Control-NAC & $13.83 \pm 0.85$ & 0.000 & $(11.459,16.202)$ \\
\cline { 2 - 5 } & SM-NAC & $1.29 \pm 0.85$ & 0.348 & $(-1.080,3.664)$ \\
\hline \multirow{3}{*}{ ROS (\%) } & Control-SM & $3.66 \pm 0.54$ & 0.000 & $(2.138,5.174)$ \\
\cline { 2 - 5 } & Control-NAC & $4.65 \pm 0.54$ & 0.000 & $(-0.524,2.512)$ \\
\cline { 2 - 5 } & SM-NAC & $0.99 \pm 0.54$ & 0.230 & $(0.080,0.108)$ \\
\hline \multirow{3}{*}{ Lipid peroxidation } & Control-SM & $0.09 \pm 0.01$ & 0.000 & $(0.083,0.111)$ \\
\cline { 2 - 5 } & Control-NAC & $0.10 \pm 0.01$ & 0.000 & $(-0.011,0.017)$ \\
\cline { 2 - 5 } & SM-NAC & $0.00 \pm 0.01$ & 0.806 & \\
\hline
\end{tabular}

Table 3: Cell viability, ROS and lipid peroxidation differences comparison.

\begin{tabular}{|c|c|c|c|c|c|}
\hline VSMC & Control & SM & NAC & F value & P value \\
\hline \multicolumn{7}{|c|}{ Rest } \\
\hline Cell Viability (\%) & $47.45 \pm 1.49$ & $34.91 \pm 1.26$ & $33.62 \pm 1.28$ & 161.265 & 0 \\
\hline ROS (\%) & $19.49 \pm 0.98$ & $15.83 \pm 0.81$ & $14.84 \pm 0.78$ & 40.427 & 0 \\
\hline Lipid peroxidation & $0.38 \pm 0.01$ & $0.29 \pm 0.01$ & $0.28 \pm 0.01$ & 237.454 & 0 \\
\hline \multicolumn{7}{|c}{ Homocysteine } \\
\hline
\end{tabular}


Journal of Complementary Medicine \& Alternative Healthcare

\begin{tabular}{|c|c|c|c|c|c|}
\hline Cell Viability (\%) & $100 \pm 0.00$ & $48.17 \pm 1.21$ & $48.01 \pm 0.80$ & 6428.153 & 0 \\
\hline ROS (\%) & $42.93 \pm 1.25$ & $18.22 \pm 0.84$ & $17.79 \pm 0.68$ & 1099.746 & 0 \\
\hline Lipid peroxidation & $0.59 \pm 0.02$ & $0.39 \pm 0.01$ & $0.38 \pm 0.01$ & 544.751 & 0 \\
\hline
\end{tabular}

\section{Inhibitory reactive oxygen species of A10 cells with Salvia miltiorrhiza}

The results of intracellular ROS measurement (Figure 3) revealed the mean value of control group was $19.49 \pm 0.98 \%$ on the rest cultured VSMC, but significantly decreased to $15.83 \pm 0.81 \%$ in the SM group or $14.84 \pm 0.78 \%$ in the NAC group $(\mathrm{P}<0.001)$. Scheffe test (Table 1) noted that the mean of difference $3.66 \pm 0.54 \%$ between control group and SM group was statistically significant (95\% CI: 2.138 5.174\%). The other mean of difference $4.65 \pm 0.54 \%$ between control group and NAC group was also statistically significant (95\% CI: 3.132 6.168\%). However, there was no significant difference $0.99 \pm 0.54 \%(95 \%$ CI: $0.524 \sim 2.512 \%$ ) between SM and NAC group. Homocysteine $(100 \mu \mathrm{M})$ can significantly increase A10 cells intracellular ROS level $(\mathrm{P}<0.001)$, but would be reduced by SM or NAC treatment. The mean value of control group was $42.93 \pm 1.25 \%$ on the homocysteine induced VSMC culture, but significantly decreased to $18.22 \pm 0.84 \%$ in the SM group or $17.79 \pm 0.68 \%$ in the NAC group $(\mathrm{P}<0.001)$. Scheffe test (Table 2$)$ revealed that the mean of difference $23.71 \pm 0.60 \%$ between control group and SM group was statistically significant (95\% CI: 22.031 25.389\%). The other mean of difference $25.14 \pm 0.60 \%$ between control group and NAC group was also statistically significant (95\% CI: 23.463 26.821\%). However, there was no significant difference $1.43 \pm 0.60 \%$ (95\% CI: $0.247 \sim 3.111 \%$ ) between SM and NAC group. The results demonstrated that SM $0.015 \mathrm{mg} / \mathrm{ml}$ and NAC $16 \mathrm{ng} / \mathrm{ml}$ did reduce intracellular ROS of A10 cells on with or without homocysteine induced VSMC culture (Table 3).

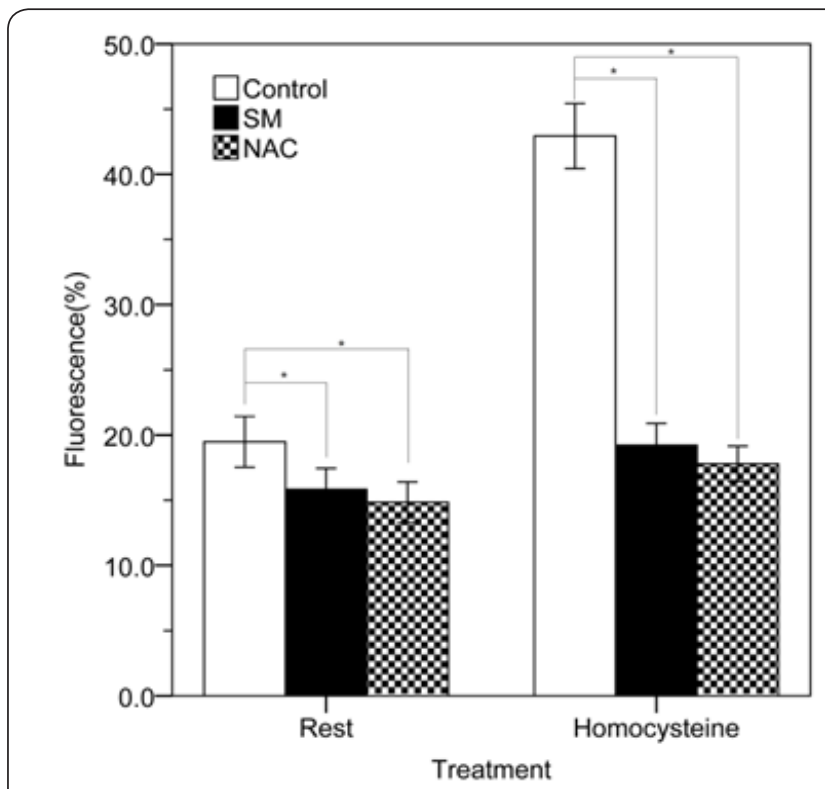

Figure 3: Effect of SM upon the A10 cells intracellular ROS as measured by the DCFH method.

\section{Inhibitory lipid peroxidation of A10 cells with Salvia miltiorrhiza}

The results of lipid peroxidation measurement (Figure 4) showed the mean value of control group was $0.38 \pm 0.01$ on the rest cultured VSMC, but significantly decreased to $0.29 \pm 0.01$ in the SM group or $0.28 \pm 0.01$ in the NAC group $(\mathrm{P}<0.001)$. Scheffe test (Table 1) revealed that the mean of difference $0.09 \pm 0.01$ between control group and SM group was statistically significant (95\% CI: $0.080 \sim 0.108$ ). The other mean of difference $0.10 \pm 0.01$ between control group and NAC group was also statistically significant (95\% CI: 0.083 0.111). However, there was no significant difference $0.00 \pm 0.01$ (95\% CI: 0.011 0.017) between SM and NAC group. Homocysteine $(100 \mu \mathrm{M})$ can significantly increase A10 cells lipid peroxidation level $(\mathrm{P}<0.001)$, but would be reduced by SM or NAC treatment. The mean value of control group was $0.59 \pm 0.02$ on the homocysteine induced VSMC culture, but significantly decreased to $0.39 \pm 0.01$ in the SM group or $0.38 \pm 0.01$ in the NAC group $(\mathrm{P}<0.001)$. Scheffe test (Table 2) revealed that the mean of difference $0.19 \pm 0.01$ between control group and SM group was statistically significant (95\% CI: $0.174 \sim 0.213$ ). The other mean of difference $0.21 \pm 0.01$ between control group and NAC group was also statistically significant (95\% CI: 0.191 0.230). However, there was no significant difference $0.02 \pm 0.01$ (95\% CI: 0.003 0.036) between SM and NAC group. These results demonstrated that SM $0.015 \mathrm{mg} / \mathrm{ml}$ and NAC $16 \mathrm{ng} / \mathrm{ml}$ did improve lipid peroxidation of A10 cells on the with or without homocysteine induced VSMC culture (Table $3)$.

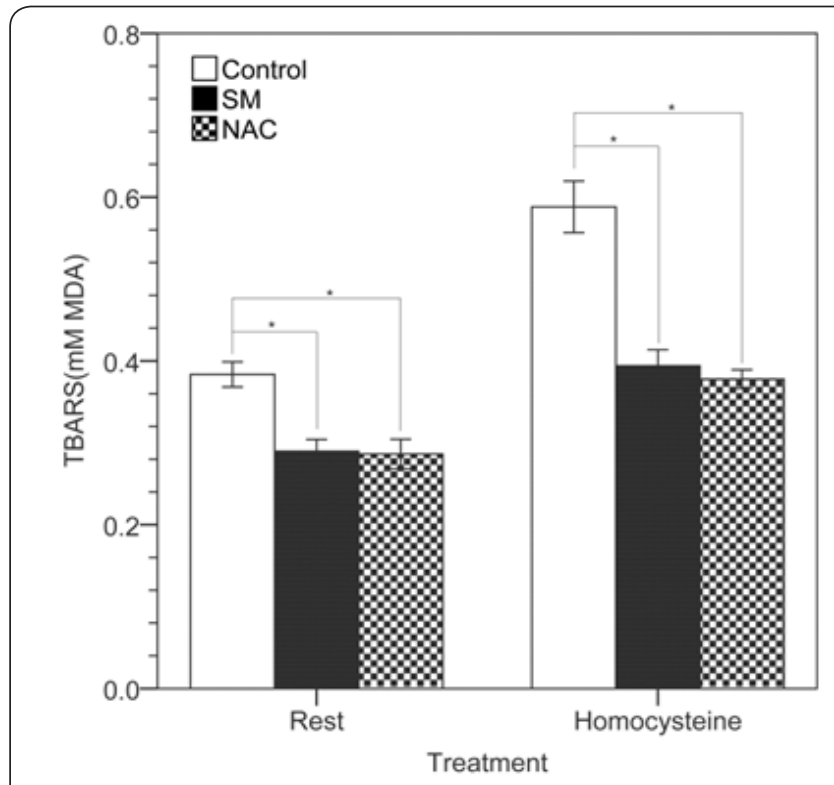

Figure 4: Effect of SM upon the A10 cells lipid per oxidation as measured by the TBARS assay. 


\section{Discussion and Conclusion}

Through activating circulation and dispersing blood stasis, interpretation of Traditional Chinese Medicine, SM could be used to treat blood stasis syndrome before. Until now, SM is still the most commonly used Chinese herb in cardiovascular $[15,27]$ and cerebrovascular diseases $[17,18]$. It mainly contains the hydrophilic phenolic acids and the lipophilic tanshinones [28] which may have some pharmacological effects including cardioprotection, neuroprotection, anticancer, anti-inflammation and antifibrosis $[29,30]$.

The morphology of spindle shape was changed by SM treatment. It would represent the condition that the VSMCs treated with SM were not in the active synthetic phenotype. SM may reduce the growth of VSMCs (Figure 1) to inhibit the pathological process of atherosclerosis.

In addition to the general control group, homocysteine was used as a negative control and NAC was used as a positive control for SM research on the cultured A10 cells. Homocysteine could be the high risk factor of atherosclerosis and induce proliferation and migration of VSMCs $[19,20]$. Another NAC is a strong antioxidant $[21,22]$. This study noted that homocysteine could induce more cell viability, intracellular ROS, and lipid peroxidation of VSMCs, but reduced by SM or NAC treatment. Both SM and NAC can significantly decrease VSMCs cell viability, intracellular ROS, and lipid peroxidation on the rest or homocysteine-induced VSMCs (Table 3).

Excessive ROS and oxidative stress can cause endothelium dysfunction, lipid peroxidation, and vascular inflammation [31]. They would regulate differentiation and contractility of VSMCs and lead to vascular remodeling in the initiation and progression of atherosclerosis $[32,33]$. Another lipid oxidation products and oxidized low-density lipoproteins could impair platelet- derived growth factor receptor activity and induce smooth muscle cell migration and proliferation in the vessel [34]. This study demonstrated that SM may be similar to NAC with antioxidant capacity and could inhibit VSMCs proliferation with suppressing intracellular ROS and lipid peroxidation. SM may reduce ROS production through downregulating oxidizes, superoxide, oxidative modification of LDLs, mitochondrial oxidative stress, but up regulating catalase, MnSOD, glutathione peroxidase and coupled eNOS [14].

No advanced molecular research about antioxidative mechanism of SM was the limitation of this study. Another limitation of this study was not carried out on the hydrophilic phenolic acids and the lipophilic tanshinones. However, the conclusion of this pilot study is SM could inhibit VSMCs proliferation with suppressing intracellular ROS and lipid peroxidation, which still can be used as a reference for further molecular medicine or clinical research.

\section{References}

1. Herrington W, Lacey B, Sherliker P, Armitage J, Lewington S (2016) Epidemiology of atherosclerosis and the potential to reduce the global burden of atherothrombotic disease. Circ Res 118(4): 535-546.

2. Raskob GE, Angchaisuksiri P, Blanco AN, Buller H, Gallus A, et al. (2014) Thrombosis: a major contributor to global disease burden. Arterioscler Thromb Vasc Biol 34(11): 2363-2371.

3. Barquera S, Pedroza-Tobías A, Medina C, Hernández-Barrera L, Bibbins-Domingo K (2015) Global Overview of the epidemiology of atherosclerotic cardiovascular disease. Arch Med Res 46(5): 328-338.

4. Lusis AJ (2000) Atherosclerosis. Nature 407(6801): 233-241.

5. GBD 2013 Mortality and causes of death collaborators (2015) Global, regional, and national age-sex specific all-cause and cause-specific mortality for 240 causes of death, 1990-2013: a systematic analysis for the Global Burden of Disease Study 2013. Lancet 385(9963): 117-171.

6. Rivard A, Andres V (2000) Vascular smooth muscle cell proliferation in the pathogenesis of atherosclerotic cardiovascular diseases. Histol Histopathol 15(2): 557-571.

7. Rudijanto A (2007) The role of vascular smooth muscle cells on the pathogenesis of atherosclerosis. Acta Med Indones 39(2): 86-93.

8. Orr AW, Hastings NE, Blackman BR, Wamhoff BR (2009) Complex regulation and function of the inflammatory smooth muscle cell phenotype in atherosclerosis. J Vasc Res 47(2): 168-180.

9. Zhang Q, Liu AD, Huang YS (2006) Clinical non-inferiority trial on treatment of coronary heart disease angina pectoris of Xin-blood stasis syndrome type with lyophilized Salvia salt of lithospermic acid powder for injection. Chin J Integr Med 12(1): 12-18.

10. Zhang SJ, Cheng ZX, Lin YW, Qin J, Cheng YH, et al. (2007) Effection of compositie salviae dropping pill on hyperlipemia patients with phlegm and blood stasis syndrome. Zhongguo Zhong Yao Za Zhi 32(5): 440443.

11. Chen X, Guo J, Bao J, Lu J, Wang Y (2014) The anticancer properties of Salvia miltiorrhiza Bunge (Danshen): a systematic review. Med Res Rev 34(4): 768-794.

12. Hung YC, Pan TL, Hu WL (2016) Roles of reactive oxygen species in anticancer therapy with Salvia miltiorrhiza Bunge. Oxid Med Cell Longev 2016: 5293284.

13. Chen Z, Xu H (2014) Anti-Inflammatory and Immunomodulatory mechanism of Tanshinone IIA for atherosclerosis. Evid Based Complement Alternat Med 2014: 267976.

14. Chang CC, Chang YC, Hu WL, Hung YC (2016) Oxidative stress and Salvia miltiorrhiza in aging-associated cardiovascular diseases. Oxid Med Cell Longev 2016: 4797102.

15. Hung YC, Tseng YJ, Hu WL, Chen HJ, Li TC, et al. (2015) Demographic and prescribing patterns of Chinese herbal products for individualized therapy for ischemic heart disease in Taiwan: Population-based study. PLoS One 10(8): e0137058. 
16. Tsai MY, Hu WL, Lin CC, Lee YC, Chen SY, et al. (2017) Prescription pattern of Chinese herbal products for heart failure in Taiwan: A population-based study. Int J Cardiol 228: 90-96.

17. Chang CC, Lee YC, Lin CC, Chang CH, Chiu CD, et al. (2016) Characteristics of traditional Chinese medicine usage in patients with stroke in Taiwan: A nationwide population-based study. J Ethnopharmacol 186 311-321.

18. Hung IL, Hung YC, Wang LY, Hsu SF, Chen HJ (2015) Chinese herbal products for ischemic stroke. Am J Chin Med 43(7): 1365-1379.

19. Ganguly P, Alam SF (2015) Role of homocysteine in the development of cardiovascular disease. Nutr J 14: 6.

20. Thambyrajah J, Townend JN (2000) Homocysteine and atherothrombosis--mechanisms for injury. Eur Heart J 21(12): $967-$ 974.

21. Elbini Dhouib I, Jallouli M, Annabi A, Gharbi N, Elfazaa S, et al. (2016) A minireview on N-acetylcysteine: An old drug with new approaches. Life Sci 151: 359-363.

22. De Andrade KQ, Moura FA, dos Santos JM, de Araújo OR, de Farias Santos JC, et al. (2015) Oxidative Stress and Inflammation in Hepatic Diseases: Therapeutic Possibilities of N-Acetylcysteine. Int J Mol Sci 16(12): 30269-302308.

23. Rao RS, Miano JM, Olson EN, Seidel CL (1997) The A10 cell line: a model for neonatal, neointimal, or differentiated vascular smooth muscle cells? Cardiovascular Research 36(1): 118-126.

24. Berg K, Hansen MB, Nielsen SE (1990) A new sensitive bioassay for precise quantification of interferon activity as measured via the mitochondrial dehydrogenase function in cells (MTT-method). Acta Pathologica, Microbiologica, Immunologica Scandinavica 98: 156-162.

25. Wang H, Joseph JA (1999) Quantifying cellular oxidative stress by dichlorofluorescein assay using microplate reader. Free Radical Biology \& Medicine 27: 612-616.
26. Janero DR (1990) Malondialdehyde and thiobarbituric acid-reactivity as diagnostic indices of lipid peroxidation and peroxidative tissue injury. Free Radic Biol Med 9(6): 515-540.

27. Zhang Y, Xie Y, Liao X, Jia Q, Chai Y (2017) A Chinese patent medicine Salvia miltiorrhiza depside salts for infusion combined with conventional treatment for patients with angina pectoris: A systematic review and meta-analysis of randomized controlled trials. Phytomedicine 25: 100-117.

28. Ma XH, Ma Y, Tang JF, He YL, Liu YC, et al. (2015) The biosynthetic pathways of tanshinones and phenolic acids in Salvia miltiorrhiza. Molecules 20(9): 16235-16254.

29. Su CY, Ming QL, Rahman K, Han T, Qin LP (2015) Salvia miltiorrhiza: traditional medicinal uses, chemistry, and pharmacology. Chin J Nat Med 13(3): 163-182.

30. Zhou L, Zuo Z, Chow MS (2005) Danshen: an overview of its chemistry, pharmacology, pharmacokinetics, and clinical use. J Clin Pharmacol 45(12): 1345-1359.

31. Chen Q Wang Q Zhu J, Xiao Q, Zhang L (2017) Reactive oxygen species: key regulators in vascular health and diseases. Br J Pharmacol.

32. Vara D, Pula G (2014) Reactive oxygen species: physiological roles in the regulation of vascular cells. Curr Mol Med 14(9): 1103-1125.

33. Staiculescu MC, Foote C, Meininger GA, Martinez-Lemus LA (2014) The role of reactive oxygen species in microvascular remodeling. Int J Mol Sci 15(12): 23792-23835.

34. Vindis C, Escargueil-Blanc I, Uchida K, Elbaz M, Salvayre R, et al. (2007) Lipid oxidation products and oxidized low-density lipoproteins impair platelet-derived growth factor receptor activity in smooth muscle cells: implication in atherosclerosis. Redox Rep 12(1): 96-100.

Your next submission with Juniper Publishers
will reach you the below assets
- Quality Editorial service
- Swift Peer Review
- Reprints availability
- E-prints Service
- Manuscript Podcast for convenient understanding
- Global attainment for your research
- Manuscript accessibility in different formats
( Pdf, E-pub, Full Text, Audio)
- Unceasing customer service
Track the below URL for one-step submission
https://juniperpublishers.com/online-submission.php

